\title{
Correction to "Individual Differences in Metabolic Clearance of S-Warfarin Efficiently Mediated by Polymorphic Marmoset Cytochrome P450 2C19 in Livers"
}

\begin{abstract}
In the above article [Uehara S, Uno Y, Inoue T, Kawano M, Shimizu M, Toda A, Utoh M, Sasaki E, and Yamazaki H (2016) Drug Metab Dispos 44:911-915 DOI: https://doi.org/10.1124/dmd.116.070383], the amino acid mutation of Thr469IIe in marmoset liver microsomal P450 2C19 was incorrectly provided as Ile469Thr for the Abstract, Introduction, Figs. 1 and 2 captions, Table 2, Results, and Discussion. The novel marmoset liver P450 2C19 variant p.[(Phe7Leu; Ser254Leu; Thr469IIe)] was correctly identified in the in vitro and in vivo study.
\end{abstract}

The HTML version of the article has been corrected.

The author apologizes for this error and any inconvenience it may have caused. 